\title{
The use of the recognition heuristic as an investment strategy in European stock markets
}

\author{
Júlio Lobão \\ School of Economics and Management, University of Porto, Porto, Portugal \\ Luís Pacheco \\ Department of Economics, Management and Computer Sciences, \\ Portucalense University, Porto, Portugal, and \\ Carlos Pereira \\ School of Economics and Management, University of Porto, Porto, Portugal
}

Received 26 January 2017 Accepted 1 April 2017

\begin{abstract}
Purpose - People often face constraints such as a lack of time or information in taking decisions, which leads them to use heuristics. In these situations, fast and frugal rules may be useful for making adaptive decisions with fewer resources, even if it leads to suboptimal choices. When applied to financial markets, the recognition heuristic predicts that investors acquire the stocks that they are aware of, thereby inflating the price of the most recognized stocks. This paper aims to study the profitability against the market of the most recognized stocks in Europe.
\end{abstract}

Design/methodology/approach - In this paper, the authors perform a survey and use Google Trends to study the profitability against the market of the most recognized stocks in Europe.

Findings - The authors conclude that a recognition heuristic portfolio yields poorer returns than a market portfolio. In contrast, from the data collected on Google Trends, weak evidence was found that strong increases in companies monthly search volumes may lead to abnormal returns in the following month.

Research limitations/implications - The applied investment strategy does not account for transaction costs, which may jeopardize its profitability given the fact that it is necessary to revise the portfolio on a monthly basis. Despite the results obtained, they are useful to understanding the performance of recognition heuristic strategies over a comprehensive time horizon, and it would be interesting to depict its viability during different market conditions. This analysis could provide additional information about a preferable scenario for employing our strategies and, ultimately, enhance the profitability of recognition heuristic strategies.

Practical implications - Through the exhaustive analysis performed here on the recognition heuristic in the European stock market, it is possible to conclude that no evidence was found for the viability of exploring this type of strategy. In fact, the investors would always gain better returns when adopting a passive investment strategy. Therefore, it would be wise to assume that the European market presents at least a degree of efficiency where no investment would yield abnormal returns following the recognition heuristic.

Originality/value - The main objective of this paper is to study the performance of the recognition heuristic in the financial markets and to contribute to the knowledge in this field. Although many authors

(C) Júlio Lobão, Luís Pacheco and Carlos Pereira. Journal of Economic Finance and Administrative Science. Published by Emerald Publishing Limited. This article is published under the Creative Commons Attribution (CC BY 4.0) licence. Anyone may reproduce, distribute, translate and create derivative works of this article (for both commercial \& non-commercial purposes), subject to full attribution to the original publication and authors. The full terms of this licence may be seen at http:// creativecommons.org/licenses/by/4.0/legalcode

JEL classification - G11, G12

\section{Use of recognition heuristic}


JEFAS

22,43

have already studied this heuristic when applied to financial markets, there is a lack of consensus in the literature.

Keywords Investment decisions, Behavioural finance, Stock returns, Financial market, Recognition heuristic

Paper type Research paper

\section{8}

\section{Introduction}

The recognition heuristic has its origins in psychology and tends to be described as a fast and frugal way of thinking to take decisions in a bounded rationality scenario.

Neoclassical financial theory assumes that individuals are fully rational and always take the optimal decision when facing a problem. However, despite support by several authors, that thought is not very realistic, as individuals often face various conditions that may lead to rational restrictions, such as inadequate time to take the decision or a lack of information. Hence, heuristics are useful to taking some shortcuts to decide faster and with fewer resources, even if that leads to suboptimal decisions. The recognition heuristic predicts that when facing a challenge to choose between two objects and only one of them is familiar, the individual will always choose the familiar object.

Introducing this concept in financial markets would be interesting to study if the most recognized stocks provide abnormal returns on a consistent basis as the result of individuals choosing to buy the stocks they are most familiar with. This would contribute to the discussion of the efficient market hypothesis (Fama, 1970) that states that no investment strategy can beat the market consistently. In recent years, the behavioural approach has also emerged, stating that financial markets are made up of individuals who can make irrational decisions, leading to inefficiencies in financial markets (Akerlof and Shiller, 2010).

The main authors who link recognition heuristic with financial markets are Borges $e t$ al. (1999), Boyd (2001) and Andersson and Rakow (2007). Nevertheless, these three studies reflect the lack of consensus about this topic, suggesting that further studies may be relevant contributions to the literature. The main objective of this paper is to study whether recognized stocks produce abnormal returns on a consistent basis. In other words, the objective is to investigate whether a portfolio constructed of the most recognized stocks of a given economy may consistently beat the market portfolio.

Following the same approach as Borges et al. (1999), Boyd (2001) and Andersson and Rakow (2007), a survey was performed to infer which stocks from the STOXX ${ }^{\circledR}$ Europe 50 are most recognized. The survey was given to 272 participants and two portfolios were constructed: the recognized portfolio and unrecognized portfolio. The performance of each portfolio was compared with the market portfolio to infer if the recognition heuristic strategy yields better returns than the market. We concluded that investing in the European market based on individual's "ignorance" does not produce any excess return.

To complement the paper, an additional methodology based on Google Trends was adopted. The use of this tool was considered as relevant to study recognition heuristic, as search volume may be used as a proxy for investor recognition. In other words, it is expected that the most recognized companies get greater investor attention on the web than the less recognized companies. As in Bank et al. (2011), three equal-sized portfolios were constructed each month: one compiled of the companies whose search volume increased the most, another of companies for whom the search volume most decreased and another of the remaining companies. Then two investment strategies relying on the recognition heuristic were tested during the period under analysis. To verify the performance of each investment strategy, the returns obtained were regressed against the risk factors included in three 
relevant market models: CAPM (Treynor, 1961, 1962; Sharpe, 1964; Lintner, 1965; Mossin, 1966), three-factor model (Fama and French, 1993) and Carhart (1997) four-factor model. Jensen's (1968) alpha was estimated to infer whether the designed investment strategies could beat the market on a consistent basis. The results showed that following a strategy based on the recognition heuristic principles it is possible to yield weak, statistically insignificant abnormal returns on a consistent basis. This investment strategy would imply having to modify the portfolio on a monthly basis, which could lead to high transaction costs that would absorb the profit of the strategy.

This paper is organized in five sections. The second section presents the literature review with the relevant authors, the third section discusses the methodologies used and the fourth section presents and analyses the results. Finally, in the fifth section, we present the main conclusions.

\section{Literature review}

\subsection{Recognition heuristic}

The recognition heuristic concept was introduced by Gigerenzer and Goldstein (1996) and Goldstein and Gigerenzer (1999, 2002). The authors intended to "exploit the vast and efficient capacity of recognition to make inferences about unknown aspects of the world" (Goldstein and Gigerenzer, 1999, p. 4).

To understand what the recognition heuristic is:

[...] consider the task of inferring which of two objects has a higher value for some criterion (e.g. which is faster, higher and stronger). The recognition heuristic for such a task is simply stated: if one of the two objects is recognized and the other is not, then infer that the recognized object has the higher value (Goldstein and Gigerenzer, 1999, p. 41).

The heuristic is non-compensatory, which means that no other information aside from recognition is taken into account in the judgment (Goldstein and Gigerenzer, 1999). This feature is also known as the less-is-more (LiME) effect. To prove this feature, Goldstein and Gigerenzer (2002) performed a test where they asked about a dozen Americans and Germans the city with the higher population - San Diego or San Antonio. About two-thirds of the Americans chose San Diego correctly, while all the German (with significantly less knowledge) answered correctly. The impressive result obtained from the German group was due to a simple fact: all the Germans tested had heard about San Diego before, and about half of them did not recognize San Antonio. This process is counterintuitive as it is shown that people with less knowledge can make better choices than people with broader knowledge about the topic.

The recognition heuristic cannot be applied to every situation or even to making correct inferences using it. The recognition heuristic is domain-specific, so it only works in environments where recognition is correlated with the criterion. According to Goldstein and Gigerenzer (1999, p. 44) "ignorance is beneficial if it is correlated with what one wishes to infer". For instance, because city size is positively associated with recognition, the recognition heuristic would predict that recognized cities would be judged as larger than unrecognized cities. Moreover, it is important to bear in mind that the recognition heuristic "does not apply to situations in which people already have conclusive criterion knowledge about the objects, which allows a response to be deduced" (Pachur et al., 2011, p. 2).

Recognition may be also easily misunderstood with completely different notions such as availability (Tversky and Kahneman, 1974) and familiarity (Griggs and Cox, 1982). As stated by Goldstein and Gigerenzer (2002, p. 77), the availability heuristic is based on recall, not recognition, with people recognizing far more items than they can recall. According to 
JEFAS

22,43

210

these authors, availability is a graded distinction among items in memory, and it is measured by the order or speed with which they come to mind or the number of instances of categories one can generate. On the other hand, the term "familiarity" is typically used in the literature to denote the degree of knowledge (or amount of experience) a person has of a task or object.

Pachur et al. (2011, p. 4) mention that collective recognition (i.e. the proportion of people in some population that recognize the object) as used by several authors for their method of analysis, are not direct implementations of the recognition heuristic, but models of individual recognition. Nevertheless, some caution is required with this type of analysis as:

[...] the cognitive processes involved would be different from the recognition heuristic (e.g. including recall of the collective recognition rates or their estimation in other ways, such as by the number of people observed to have chosen some option).

\subsection{Recognition heuristic applied to financial markets}

Merton (1987) highlighted the concept of recognition in presuming that investor attention may be relevant to stock pricing. The "investor recognition hypothesis" holds that in informationally incomplete markets, investors are not aware of all securities available for investment. Therefore, stocks with lower investor recognition need to offer higher returns to compensate their investors for being long in securities with less information available and less media coverage. Consequently, in theory, stocks with higher investor recognition earn lower returns than stocks with lower visibility. Several authors found a relationship between media coverage and returns (Engelberg and Parsons, 2011; Tetlock, 2007, 2011; Hillert et al., 2014; Lou, 2014). For instance, Fang and Peress (2009) empirically found a stable, negative relationship between media coverage and required rate of return and attributed that finding to the effect highlighted by Merton (1987).

Borges et al. (1999) were the first authors to implement the recognition heuristic in building portfolio strategies. The idea was to take advantage of a fast and frugal decision process to see if it was possible to compile a better portfolio with less knowledge than an investor would with access to plenty of information and resources. As the authors state, "the tools and information professional investment firms use for investment decisions are far beyond the ordinary person's reach" (Borges et al., 1999, p. 59). The idea was to take advantage of the recognition heuristic and form an investment portfolio relying only on one piece of information: company name recognition. No other information would be necessary (e.g. firms fundamentals, price, financial indicators, etc.).

Financial markets are quite complex and few investors are able to consistently beat the market over the years. The efficient market hypothesis (EMH) introduced by Fama (1970) assumes that investors are unboundedly rational, which leads to the conclusion that no one can consistently achieve higher returns than the market on a risk-adjusted basis, given the information available at the time the investment is made.

Borges et al. (1999) constructed several portfolios of stocks using name recognition of 500 American stocks and 298 German stocks (companies listed on the S\&P500 and Dax 30) by American laypeople and experts as well as German laypeople and experts, with a total of 480 people surveyed. On the basis of the survey, eight recognition-based portfolios were built. The "domestic recognition" portfolios were compiled of stocks that more than 90 per cent of the participants recognized for their country. The "international recognition" portfolios had the 10 most recognized stocks from the foreign country.

The results obtained by Borges et al. (1999) in the six-month period after the survey show that the "domestic recognition" portfolio outperformed the other benchmarks by a large 
margin only for German laypeople and experts. In the USA, the "domestic recognition" portfolio performed below the market index and the mutual fund industry. However, the "international recognition" portfolio obtained quite impressive results. For instance, American laypeople recognition's portfolio beat the market by 23 per cent. The aggregate results were very positive for the recognition heuristic as it had beaten the market in six out of eight tests, often by a large margin.

Borges et al. (1999) present some reasons why the recognition heuristic performed so well in the stock market. First, following the findings of Buzzell et al. (1975) and Ramanujam and Venkatraman (1984), evidence of a positive correlation was found between market share and profitability. One more reason for good performance of the recognition heuristic is the link between above-average profitability and core competence. Finally, a company name has value and it is important information for investors. The above-average returns presented by Borges et al. (1999) may also be a result of the extremely bull market during the period of the study, as well-known firms normally do well in up markets.

The call for further investigation under different market conditions was fulfilled by Boyd (2001). This author attempted to replicate the same experiment as Borges et al. (1999) in a bear market to test whether the recognition heuristic still produces good results with this condition. The method used was the same, surveying a group of students at a US business school and another group in non-business courses, with a total of 184 participants. A list of 111 stocks randomly extracted from the S\&P500 was given to them to infer the most recognized stocks.

From the participant responses, a single high-recognition test portfolio was constructed for both groups (business and non-business students), using the 23 stocks recognized by more than 90 per cent of the participants. During the following six-month period, the market portfolio lost 4.54 per cent and the highly recognized stocks portfolio registered a loss of 14.75 per cent. Out of curiosity, an additional test was also performed. A portfolio was built containing the 20 least recognized companies by the combined participant groups. The results were quite surprising. This portfolio yielded a gain of 16.27 per cent during the same six-month period. According to Boyd (2001, p. 155), "a high degree of company name recognition can lead to disappointing investment results in a down market, and it can also be beat by pure ignorance".

A similar study was performed by Andersson and Rakow (2007) attempting to replicate the findings of Borges et al. (1999). Therefore, they performed four different surveys. In the first, 53 UK psychology students provided recognition data for the 30 companies listed on the Italian MIB30 stock index. The second study surveyed 52 UK psychology students and 15 Swedish business students about recognition of UK, Swedish and Italian stocks. The authors extracted a list of 15 companies from each market index (UK FTSE 100, Swedish Stockholmbörsen and Italian MIB30). The shares selected were those with the highest volume for each stock index. In the third study, 70 UK psychology students, 78 Austrian business students and 36 Swedish business students provided recognition data for Austrian, Swedish and German stocks. A list of 48 stocks was on the survey, of which 9, 16 and 23 were randomly extracted respectively from the Austrian prime list, the Swedish A-List and the German prime standard. Finally, in the fourth study 15 Swedish business students provided recognition data for UK, Swedish and Italian stocks. Here, the stocks under analysis were the same 45 as in the second study, excepting one that had meanwhile ceased to trade.

Contrary to Borges et al. (1999), Andersson and Rakow (2007, p. 36) failed to achieve the same results, concluding that: 
JEFAS

22,43

[... ] the search for a quadratic relationship whereby intermediate levels of recognition might yield better (or worse) returns than both low and high levels of recognition also failed to show a consistent or predictable pattern.

Therefore, "ignorance" has no special advantage or disadvantage over sophisticated knowledge. Also, in contrast with the findings of Borges et al. (1999), the recognition heuristic tended to perform better in falling markets and poorly in rising ones.

One can then observe that although several studies have concluded that individuals tend to use heuristics in an adaptive way (Payne et al., 1993; Katsikopoulos and Martignon, 2006), that is, to best exploit the features of the environment in which the decision takes place, there is still no consensus on the usefulness of the recognition heuristic in the field of portfolio management.

\section{Methodology}

The study of the impact of recognition heuristic in stock market returns first requires that the recognized stocks are identified apart from the unrecognized stocks. In this study, two different approaches were used.

As in Borges et al. (1999), Boyd (2001) and Andersson and Rakow (2007), a survey was performed to infer which stocks are the most recognized from the STOXX ${ }^{\circledR}$ Europe 50 index, which is composed of 50 leading blue-chip firms in the European region. To complement this paper, an additional methodology was adopted. Google Trends was used to access keyword internet search volume variation across time as a proxy for investor recognition. Subsequently, two investment strategies were designed accordingly to the recognition heuristic principles and their profitability were compared to the market return. In other words, it was expected that the most recognized companies would present higher investor attention on the web than the less recognized companies.

\subsection{Survey}

Aligned with the methodology followed by Borges et al. (1999), Boyd (2001) and Andersson and Rakow (2007), our survey had the following structure: the first two questions merely had the objective of collecting information about the participants' nationality and age bracket. Those were followed by three questions that identified the participant's level of expertise in financial markets. Here, the participant had to describe his level of education and whether he works in the field of business/finance or not. Additionally, he was requested to answer the frequency of investments made in financial markets (such as stocks, mutual funds and futures). Closing this group of questions, the participant had to describe how often he read/watched financial news. The last question aimed to discover which stocks are most well-known from the list presented. The participant was presented with a list of the companies composing the STOXX ${ }^{\circledR}$ Europe 50 Index, from which he was asked to identify the names recognized. The company names on the list were replicated from Thomson Reuters Datastream to avoid arbitrariness and ensure that participants are presented with a standardized name selection process.

The survey was presented to participants through Google Forms and it was available in two languages: Portuguese and English. The participant had the option to choose the most suitable version. To distribute the survey in a more effective and faster method, it was decided that the webpage links for the survey should be provided through social networks, such as Facebook and LinkedIn.

As in Borges et al. (1999) and Boyd (2001), a portfolio of the stocks recognized by more than 90 per cent of the participants was constructed. Additionally, a portfolio was also constructed of the stocks whose company names were recognized by less than 10 per cent of 
the participants. The compilation of the portfolios obeyed the equally weighted rule, where each company contributes equally for the portfolio's performance. These two portfolios were then measured against the market portfolio to compare the performance of both strategies.

To avoid very similar returns to the market portfolio due to composition, the individuals who recognized more than 90 per cent of the companies, i.e. more than 45 companies were removed from this analysis. This kind of approach made it possible to analyse the return obtained per participant under the recognition heuristic principle, excluding those that knowing perfectly well the universe of stocks do not resort to the heuristic, and aggregate the results per participant's degree of expertise.

Each portfolio was valued following the equally weighted rule, so each stock may have exactly the same preponderance over the recognized portfolio. The survey was implemented in December 2014, and the portfolio was built using the Thomson Reuters Datastream opening price on 5 January 2015. The holding period was for five months, and the closing price on 5 June was chosen for liquidating the portfolios.

The return of each portfolio was compared with the STOXX ${ }^{\circledR}$ Europe 50 return and evidence of correlation between excess of return per each degree of expertise will be searched for.

\subsection{Google Trends as a proxy for investor recognition}

Given that Google search volume adequately proxies for investor attention and assuming that financial markets are characterized by incomplete information, a negative and persistent interdependence between changes in search volume and future returns would be expected (Fang and Peress, 2009). Barber and Odean (2008) defend that investors are able to choose from a large set of stocks when they want to buy; nevertheless, they only have a limited choice when selling securities. Subsequently, the increment of stock attraction should affect the buying side more than selling, mostly by particular and uninformed investors. Da et al. (2011) also measured attention using Google search volume and empirically observed that positive changes in the number of internet queries push up prices temporarily.

Measuring investor recognition is not a simple task. For instance, Fang and Peress (2009) measured the number of times that the company name appears in the newspaper as a proxy, but:

[... there is no reliable information as to the extent to which readers of a newspaper pay attention to the mention of a company in its pages. Other measures of investor attention, such as analyst coverage, institutional holdings, or advertisement expenditures, suffer from similar shortcomings (Fang and Peress, 2009, p. 240).

Nowadays, the number of search queries as an indicator of people interest has great appeal. The internet is spread across the globe and practically every investor is able to access company information on it. Search volume seems appropriate, as an internet user will only actively "Google" a specific keyword if he or she is interested in the object underlying the search term.

To obtain the search volume for each company, Da et al. (2011) used the company ticker symbol. Bank et al. (2011) opted to use the ordinary firm names, as they believed that this method captures the extent of attention the firm is receiving from a much broader, and potentially relevant, audience. The average internet user is expected to search for a firm on Google by its company name and it is not likely to use the international securities identification numbers (ISIN), German securities identification code (WKN) or other technical stock symbols. 
JEFAS 22,43

\section{4}

Bank et al. (2011) used Google Trends to access the search volume of firm names as a proxy for investor attention and study the implications for trading activity, liquidity and returns for German stocks. They concluded that:

[.. . ] search volume is indeed a powerful measure of investor recognition. In particular, an increase in Internet search volume is related to higher trading activity, improved stock liquidity, and leads to higher future returns in the short-run (Bank et al., 2011, p. 240).

In this study, we used the same approach as Bank et al. (2011), where common company names functioned as a proxy to access firm's recognition level. The purpose of the analysis was to infer whether increments in Google searches may lead to higher returns for the related stock in the following month. Furthermore, Google Trends has the option to specify the environment for each keyword to be used. For instance, if we insert ALLIANZ in the search tool, we have the option to specify the search volume for searches related to the financial services company. This option was used to empower the effectiveness of the search, to select the searches that concern the company name and reject the searches that may be related to other topics.

As Google is the most used search engine worldwide, the choice of Google Trends was obvious to proceed with our study. The only downside is that the search volume of a specific keyword is not given in absolute terms, but as a value relative to the total number of searches on Google during a given time interval. Therefore, for each keyword analysed this relative value is normalized to the interval between 0 and 100, where 100 represent the period in which the search volume was the highest in the time interval under analysis and 0 is obtained when the search volume does not reach a designated search volume threshold (Bank et al., 2011). These data transformation performed by Google inhibits us from comparing absolute search volume between keywords; nevertheless, we still can individually infer the behaviour of each company's popularity across time.

Each stock compiling the STOXX® All Europe 50 was accessed for its search index value given by Google Trends and the time interval for the analysis was from January 2004 to April 2015. The time interval was chosen based on the data availability for Google Trends, as January 2004 was the starting point for Google registering of search volume. Also, having slightly more than 10 years of data allows measuring the correlation between increases in stock returns with previous increments of company popularity. To perform this analysis monthly data was used.

Furthermore, as in Bank et al. (2011), and to avoid portfolio distortions, this study only included companies where the search volume is provided for more than five months. From these, all the companies where the search volume equals zero for two or more consecutive months were excluded. Following this approach, only the data related to Anheuser-Busch Inbev, Lloyds Banking Group and Glencore PLC were left out the study. Also, following the methodology adopted by Bank et al. (2011), the monthly data collected in Google Trends was sorted into three quantiles of equal size each month accordingly to the change in search value. From there, three different portfolios were constructed every month for the following month's investing: one comprised 33 per cent of companies with highest increase in search volume, another, 33 per cent of companies with highest decrease in search volume and the final portfolio was made up of 33 per cent of companies with smallest variation in search volume. The return of each portfolio was computed as the average return for the stocks held by the portfolio in the following month. Thereafter, the time series of portfolio returns of the month after the portfolio formation was regressed on recognized risk factors by using three different market models: the CAPM model, the Fama and French (1993) three-factor model and the Carhart (1997) four-factor model. 
To complete this analysis, some investment strategies were tested using the previously constructed quantile portfolios. Therefore, to test the profitability of strategies relying on the recognition heuristic philosophy the portfolio with the highest increment in search volume was bought, as this variable is intended to function as a proxy of investor recognition. Additionally, a more aggressive strategy was used, where the portfolio with the highest increment in search volume was also bought, and it was shorted in the portfolio from which the search volume most decreased (zeroinvestment strategy).

As the investor will receive the return of the following month, the first two months of data are necessary to compute the change in Google Trends variable, so the period where returns were analysed spans from March 2004 to April 2015.

\section{Analysis of results}

\subsection{Survey}

The survey was performed during December 2014 and intended to infer which stocks from the STOXX ${ }^{\circledR}$ Europe 50 Index were most recognized by the participants.

During this period, answers were collected from 272 participants. Most of the participants were Portuguese (91.55 per cent), followed by Vietnamese (2.94 per cent) and Indian (1.10 per cent), reflecting that most of them were from the University of Porto. More than half of the participants were aged between 18 and 25 years and slightly more than 96 per cent were aged 40 years or less.

Regarding the company names identified by each individual, on average each participant identified a total of 21 companies. Additionally, only 3.31 per cent of the participants were able to recognize 40 or more company names, while 8.82 per cent recognized less than 10 companies (Table I).

As mentioned in the previous section, the companies recognized by more than 90 per cent of the participants were chosen to be part of the highly recognized portfolio. On the other hand, the company names recognized by less than 10 per cent were selected for the unrecognized portfolio. In Table II, we can observe the composition of both portfolios built on 5 January 2015, which were liquidated on 5 June, after holding them for five months without performing any reallocation.

Before analysing the returns provided by each portfolio, it is important to mention that all the rates of return presented below were calculated excluding the transaction costs, that is, all the costs associated with building, maintaining and liquidating the portfolios.

Figure 1 presents the cumulative average returns for the three portfolios under analysis: the highly recognized, unrecognized and the market portfolios, which are represented here by the performance of the STOXX ${ }^{\circledR}$ Europe 50 Index. At a glance, it is possible to verify

Table I.

Number of company names identified 
JEFAS

22,43

216

\begin{tabular}{lrr}
\hline & \multicolumn{2}{c}{ Participants that identified the company } \\
Company & No. & $(\%)$ \\
\hline Barclays & 264 & 97.1 \\
Nestle & 259 & 95.2 \\
Banco Santander & 255 & 93.8 \\
Siemens & 254 & 93.4 \\
Vodafone & 249 & 91.5 \\
Deutsche Bank & 247 & 90.8 \\
Axa & 246 & 90.4 \\
Bae Systems & 27 & 9.9 \\
Reckitt Benckiser & 26 & 9.6 \\
Lvmh Moet Hennessy & 25 & 9.2 \\
BHP Billiton & 23 & 8.5 \\
National Grid & 20 & 7.4 \\
CieFinanciere Richemont & 15 & 5.5 \\
Glencore PLC & 15 & 5.5 \\
BG GRP & 14 & 5.1 \\
BT GRP & 12 & 4.4 \\
Anheuser-Busch Inbev & 11 & 4.0 \\
Astrazeneca & 0 & 0.0
\end{tabular}

Table II.

Highly recognized portfolio

By the authors

Figure 1.

Portfolio cumulative average return

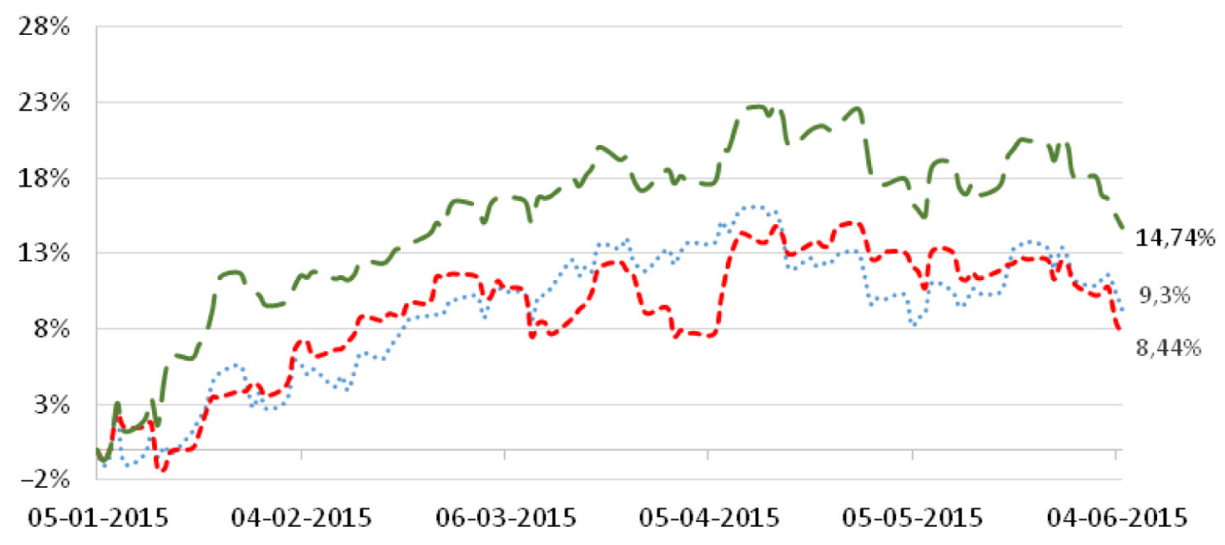

…..... Highly Recognized portfolio -----Unrecognized portfolio - - STOXX Europe 50

By the authors

that the market portfolio yielded the greatest return, 14.7 per cent from January until June. The least profitable portfolio was the unrecognized portfolio, with a return of 8.44 per cent, slightly below the highly recognized portfolio (9.3 per cent).

Nonetheless, the risk factors inherent to each investment strategy should also be discussed. In other words, the risk that investors incur when they are exposed to the different investment strategies must be accessed. 
According to Table III, the daily standard deviation for the highly recognized portfolio ( 0.99 per cent) and for the unrecognized portfolio ( 0.93 per cent) is very similar to the market standard deviation (0.95 per cent). Furthermore, by analysing the portfolio Betas, it is possible to conclude that both the highly recognized portfolio and the unrecognized portfolio succeed well in replicating the market price movements, presenting a Beta equal to 1.05 and 1.01 , respectively.

Therefore, it is possible to infer that all the three portfolios present an almost equal level of risk and, in consequence, the level of return provided by each portfolio really differentiates that the market portfolio is, by far, the most profitable portfolio.

In a nutshell, during the period considered for this analysis, the best strategy was to hold the market portfolio, although the highly recognized portfolio still yielded better returns than the unrecognized portfolio.

The results obtained here contrast with Borges et al. (1999), who also experienced an extremely bull market and the recognition heuristic portfolio yielded better returns than the market portfolio. Our results fit the findings of Andersson and Rakow (2007), who concluded that the recognition heuristic has special advantage neither over sophisticated knowledge nor the market.

Recalling Pachur et al. (2011, p. 4) on collective vs individual recognition problems, we adopt a different approach from previous studies and infer whether a participant would yield better returns by investing in companies he recognizes and the level of "ignorance" he possesses. Therefore, for each participant in this survey a portfolio was constructed of the stocks that the participant recognized. The portfolio return was also computed using the holding period from 5 January 2015 until 5 June 2015 and the portfolio was equally weighted for each stock.

The main goal was to see whether investors with less knowledge in financial markets (who identified fewer companies) would yield better returns than investors who have a broader knowledge in this field (identifying most of the companies). Moreover, each participant was ranked according to their stock market experience. To access the experience of each participant we took the data obtained for education level, frequency that the participant read financial news and frequency that they invest in the financial markets.

Nonetheless, the information collected is categorical, so it is necessary to transform it into a numerical format to be able to infer if more experienced participants yield less or more returns that less experienced ones. To do that, an experience rank was created which attributed points for the answers for each question to rank the participant. The overall experience level was obtained by summing the experience points obtained for each of the three questions.

At this stage, it is possible to infer whether the portfolio return (r) depends on the number of companies identified (CI) and the experience rank (ER) for each investor, using the following equation:

\begin{tabular}{lcccc}
\hline Portfolio & Cumulative average return (\%) & Daily average return (\%) & Daily SD (\%) & Beta \\
\hline Highly recognized & 9.29 & 0.09 & 0.99 & 1.05 \\
Unrecognized & 8.44 & 0.08 & 0.93 & 1.01 \\
Market & 14.74 & 0.13 & 0.95 & 1.00
\end{tabular}

Notes: The portfolio Beta was calculated as the average Beta for each stock composing the portfolio; Data were collected from Thomson Reuters Datastream. By the authors

Table III.

Portfolio's return and risk characteristics 
JEFAS

22,43

218

$$
R_{i}=a_{i}+\beta_{1} C I_{i}+\beta_{2} E R_{i}
$$

The results of the estimation of equation (1) are presented in Table IV.

The $R^{2}$ for this model is 0.222132 , which means that approximately 22.2 per cent of the model variability can be explained by the variables included in this analysis. Moreover, the model is statistically significant with an $F$-statistic of 38.40854 , which represents a $p$-value of 0.000 .

Individually, the companies identified variable is statistically relevant for this model for a significance level lower than 1 per cent. Nonetheless, the relationship between this variable is positive with the portfolio return. In fact, for each additional stock identified the investor is expected to gain an additional 0.0892 per cent return. This finding is contrary to the "less is more" feature of the recognition heuristic.

Regarding the experience rank the effect that it produces in the portfolio return is expected in recognition heuristic philosophy, which dictates that less experienced investors will yield higher returns. In fact, each additional experience point earned decreases the portfolio return by 0.0222 per cent.

\subsection{Google Trends as a proxy for investor's recognition}

The search volume functions as a proxy for investor recognition; thus, increments of this variable should also denote higher company recognition. Consequently, two investment strategies were used to test whether by relying on the recognition heuristic principles it was possible to yield abnormal returns in the European stock market.

In Figure 2, we observe the performance of a $100 €$ investment from February 2004 until April 2015 in three different strategies: investing in the Market portfolio, investing in Panel A - which represents the strategy of buying those stocks that had the most increase in search volume each month - and investing in Panel B, which is an extension of the previous panel by also shorting the stocks where the search volume decreased the most. From Figure 2, it is possible to infer that the market strategy was the most profitable during the entire period under analysis.

Panel A, which is the conservative strategy adopted following the recognition heuristic principles, was the second most profitable strategy. Additionally, it can be graphically observed that this strategy managed to replicate the market with less volatility.

The performance of the most aggressive strategy employed, Panel B, was mostly flat during the entire period. In fact, a 100€ investment in this strategy on February 2004 would only be worth $102 €$ in August 2015, more than 10 years later. The main reason for this performance is that both portfolios contained in this investment performed very similarly during the entire period, where the gains of the portfolio held were cancelled by shorting the other portfolio.

Table IV.

Company recognition and experience rank effect on portfolio return

\begin{tabular}{lcr}
\hline Parameter & Coefficient/value & Std. error \\
\hline A & $0.090796^{* * * *}$ & 0.002166 \\
Companies identified & $0.000892^{* * * *}$ & 0.000111 \\
Experience rank & $-0.000222^{*}$ & 0.000134 \\
$R^{2}$ & 0.222132 & \\
$F$-statistic & $38.40854^{* * *}$ &
\end{tabular}

Notes: *** Significant level at $1 \%$ level; ** significant at $5 \%$ level; * significant at $10 \%$ level From authors 


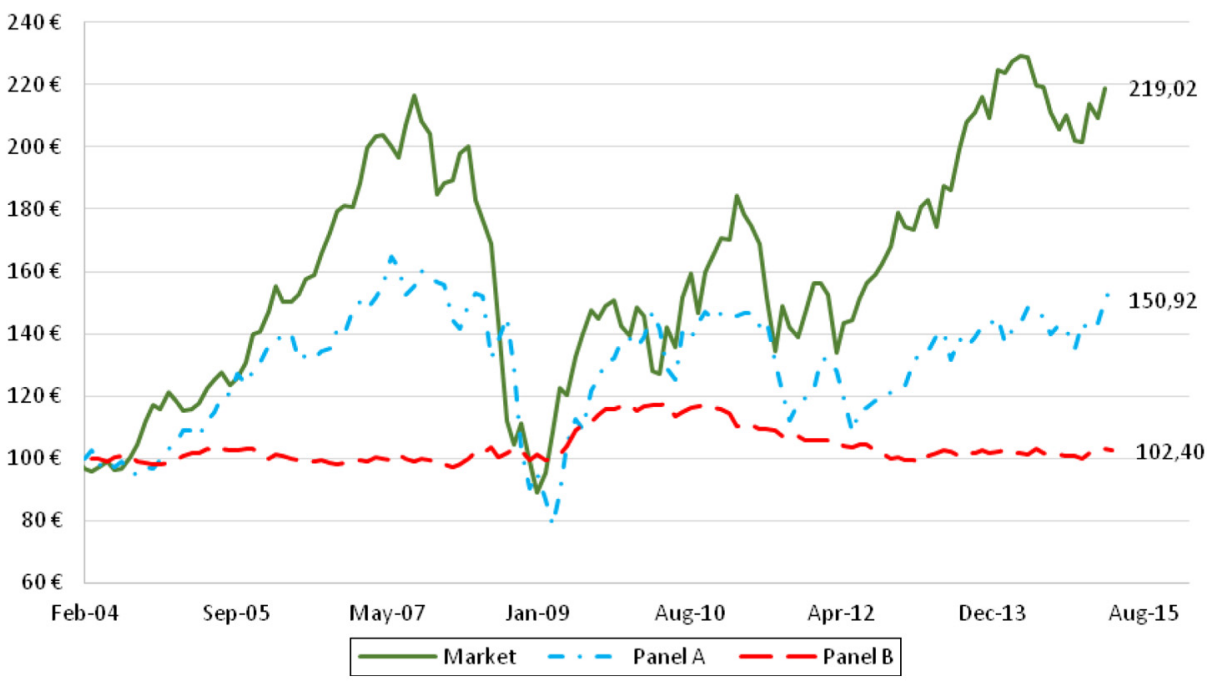

By the authors

Figure 2.

Return on a $100 €$ investment from February 2004 until April 2015

To depict the risk-adjusted performance, these strategies were regressed with the CAPM model, the three-factor model from Fama and French (1993) and the Carhart (1997) fourfactor model. The use of Jensen's $\alpha$ helps to determine whether an investment strategy is earning the proper return for its level of risk, ultimately indicating whether it beat the market.

In Table $\mathrm{V}$, we can observe the regressed coefficients for each strategy in the described market models.

From Panel A, which represents the investment strategy that follows the recognition heuristic principles in a conservative approach - buying the portfolio with greatest increment in search volume, it is possible to observe that the Jensen's $\alpha$ measures are positive in the three models, showing that that strategy was able to beat the market during the period under analysis.

Nevertheless, in the three models the variable is statistically insignificant for every significant level equal to or lower than 10 per cent. Therefore, the Jensen's $\alpha$ is not statistically different from 0 . As a consequence, Jensen's $\alpha$ measures are not positive enough to infer that the recognition heuristic may lead to greater returns in the European stock market.

The investment strategy $\beta$ for the CAPM model is 0.187 , which means that the investment strategy followed in Panel A is a lot less risky than the market. Therefore, any attempt to solely compare the average returns of this strategy on a market index without explicit adjustment for differential riskiness would be highly biased against the funds.

Regarding Panel B, this represents a more aggressive variant of the recognition heuristic principles, buying the stocks that had the most search volume increase in the previous month and shorting the stocks where the search volume most decreased, the Jensen's $\alpha$ are negative for the CAPM and the FF three-factor model and 0.000 for the $\mathrm{C}$ four-factor model. Nevertheless, all three Jensen's $\alpha$ 's are also statistically insignificant with significance levels equal or lower than 10 per cent. Therefore, these $\alpha$ s are not statistically different from 0 , 


\section{JEFAS 22,43}

Table V.

Trading profits related to Google search volume

\begin{tabular}{lcrr}
\hline Estimation & \multicolumn{1}{c}{ CAPM } & FF three-factor & C four-factor \\
\hline Panel A: Buy the portfolio with highest increment in search volume & \\
Intercept (Jensen's $\alpha$ ) & $0.002(0.004)$ & $0.002(0.004)$ & $0.003(0.004)$ \\
$R_{m t}-R_{f t}$ & $0.187^{* * *}(0.077)$ & $0.0154^{*}(0.090)$ & $0.128(0.091)$ \\
$S M B_{t}$ & - & $0.930^{* * * *}(0.224)$ & $0.915^{* * *}(0.223)$ \\
$H M L_{t}$ & - & $0.125(0.233)$ & $0.005(0.245)$ \\
$W M L_{t}$ & - & - & $-0.187(0.124)$ \\
$R^{2}$ & 0.042 & 0.155 & 0.170 \\
$F$-statistic & $5.832^{* *}$ & $7.965^{* * *}$ & $6.606^{* * *}$
\end{tabular}

Panel B: Buy the portfolio with highest increment in search volume and sell the portfolio from which the search volume most decreased

$\begin{array}{lc}\text { Intercept (Jensen's } \alpha) & -0.001(0.001) \\ R_{m t}-R_{f t} & 0.055^{* * *}(0.019) \\ S M B_{t} & - \\ H M L_{t} & - \\ W M L_{t} & - \\ R^{2} & 0.061 \\ F \text {-statistic } & 8.611^{* * *}\end{array}$

$$
\begin{gathered}
0.000(0.001) \\
0.037(0.023) \\
-0.024(0.057) \\
-0.020(0.063) \\
-0.082^{* *}(0.0316) \\
0.112 \\
4.057^{* * *}
\end{gathered}
$$

Notes: This table depicts the profitability of trading strategies described in Panels A and B; standard errors are provided in parentheses; number of observations: 134; ***significant level at $1 \%$ level; *** significant at $5 \%$ level; * significant at $10 \%$ level.

Sources: By the authors; e-views 8

which means that the Panel B strategy is not capable of beating the market consistently, considering a confidence level of 90 per cent.

During the period under analysis, a rising market was experienced, where strategies relying on recognition heuristic philosophy should yield better returns for their investors (Borges et al., 1999; Boyd, 2001). Nevertheless, as in Borges et al. (1999), the results obtained here provide weak signs that investment strategies based on the recognition heuristic may yield abnormal returns. Additionally, it is necessary to assume that no transaction costs were accounted for in this study. In fact, the investment strategy presented here requires portfolio adjustments on a monthly basis to keep the most searched-for companies in the portfolio. Therefore, given the results obtained, it would be wise to assume that a passive investment strategy would be more profitable than following the investment strategy proposed earlier.

\section{Conclusions}

The main objective of this paper is to study the performance of the recognition heuristic in the financial markets and to contribute to the knowledge in this field. Although many authors have already studied this heuristic when applied to financial markets there is a lack of consensus in the literature.

The three main papers from the authors referred to were mainly applied to the US and German markets, apart from Andersson and Rakow (2007) who extended their analysis to a few other European economies. In this sense, it was valuable to study the recognition heuristic in the European market as a whole to infer the profitability of investment strategies related to this heuristic. To proceed with this study, two different approaches were undertaken. 
The first method replicated the methodology adopted from previous studies, performing a survey to understand which companies were the most recognized by the participants. Subsequently, two portfolios were constructed, one compiled of the highly recognized companies and other of the less recognized companies. The returns were then compared with the market.

The second method was more innovative and designed to take advantage of new sources of data available, to study whether the fast and frugal recognition heuristic may also be applied to financial markets. Taking advantage of Google Trends, monthly internet search volume data were collected, and statistical software was used to infer the impact of changes in search volume on future stock returns. To do that, three equal size portfolios were constructed each month: one with the companies that mostly increased in search volume, another with the companies that mostly decreased in search volume and the last with the companies that verified small changes in search volume. Then, two investment strategies were developed based on the recognition heuristic principles, and the returns for those strategies were regressed using the most relevant market models: the CAPM model, the Fama and French three-factor model and the Carhart four-factor model. Jensen's alpha was estimated to infer whether the designed investment strategies could beat the market on a consistent basis.

From the first method, it was possible to conclude that the market portfolio performed much better than the recognized portfolio during the observation period (yielding 14.7 against 9.29 per cent), which in turn beat the unrecognized portfolio (8.44 per cent) by a tiny margin. It is important to note that all three portfolios presented similar levels of risk, measured by the daily standard deviation and the portfolio beta. This finding was not expected by the previous studies that claim that recognition heuristic strategies yield greater returns during bullish periods (Borges et al., 1999). Moreover, we checked the "individual recognition" where several portfolios were constructed, one for each participant with the companies identified. It was found that the most successful participants were those who recognized more companies, contradicting the "less is more" effect of the recognition heuristic.

Regarding the Google Trends study, the results indicated that the strategy based on the recognition heuristic principles yielded weak but statistically insignificant abnormal returns on a consistent basis. Nevertheless, the investment strategy would imply having to modify the portfolio on a monthly basis, which would lead to high transaction costs that could absorb the strategy profitability. Therefore, it is possible to conclude that following the investment strategy based on recognition heuristic principles would not produce better returns to investors than investing in the market portfolio.

Through the exhaustive analysis performed here on the recognition heuristic in the European stock market, it is possible to conclude that no evidence was found for the viability of exploring this type of strategy. In fact, the investors would always gain better returns when adopting a passive investment strategy.

Therefore, it would be wise to assume that the European market presents at least a degree of efficiency where no investment would yield abnormal returns following the recognition heuristic.

Despite the results obtained, they are useful to understanding the performance of recognition heuristic strategies over a comprehensive time horizon, and it would be interesting to depict its viability during different market conditions. This analysis could provide additional information about a preferable scenario for employing our strategies and, ultimately, enhance the profitability of recognition heuristic strategies. 


\section{JEFAS 22,43}

\section{References}

Akerlof, G.A. and Shiller, R.J. (2010), Animal Spirits: How Human Psychology Drives the Economy, and Why It Matters for Global Capitalism, Princeton University Press, Princeton, NJ.

Andersson, P. and Rakow, T. (2007), "Now you see it now you don't: the effectiveness of the recognition heuristic for selecting stocks", Judgment and Decision Making, Vol. 2, pp. 29-39.

Bank, M., Larch, M. and Peter, G. (2011), "Google search volume and its influence on liquidity and returns of German stocks", Financial Markets and Portfolio Management, Vol. 25 No. 3, pp. 239-264.

Barber, B.M. and Odean, T. (2008), "All that glitters: the effect of attention and news on the buying behavior of individual and institutional investors", Review of Financial Studies, Vol. 21 No. 2, pp. $785-818$.

Borges, B., Goldstein, D.G., Ortmann, A. and Gigerenzer, G. (1999), "Can ignorance beat the stock market?", in Gigerenzer, G., Todd, P. and The ABC Research Group (Eds), Simple Heuristics That Make Us Smart, Oxford University Press, New York, NY, Oxford, pp. 59-72.

Boyd, M. (2001), "On ignorance, intuition, and investing: a bear market test of the recognition heuristic", Journal of Psychology and Financial Markets, Vol. 2 No. 3, pp. 150-156.

Buzzell, R.D., Gale, B.T. and Sultan, R.G. (1975), "Market share - a key to profitability", Harvard Business Review, pp. 97-106.

Carhart, M.M. (1997), "On persistence in mutual fund performance”, Journal of Finance, Vol. 52 No. 1, pp. $57-82$.

Da, Z.H.I., Engelberg, J. and Gao, P. (2011), "In search of attention”, The Journal of Finance, Vol. 66 No. 5, pp. 1461-1499.

Engelberg, J. and Parsons, C. (2011), “The causal impact of media in financial markets”, The Journal of Finance, Vol. 66 No. 1, pp. 67-97.

Fama, E.F. (1970), "Efficient capital markets: a review of theory and empirical work", Journal of Finance, Vol. 25 No. 2, pp. 383-417.

Fama, E.F. and French, K.R. (1993), "Common risk factors in the returns on stocks and bonds", Journal of Financial Economics, Vol. 33 No. 1, pp. 3-56.

Fang, L. and Peress, J. (2009), "Media coverage and the cross-section of stock returns", The Journal of Finance, Vol. 64 No. 5, pp. 2023-2052.

Gigerenzer, G. and Goldstein, D.G. (1996), "Reasoning the fast and frugal way: models of bounded rationality", Psychological Review, Vol. 103 No. 4, pp. 650-669.

Goldstein, D.G. and Gigerenzer, G. (1999), "The recognition heuristic: how ignorance makes us smart", in Gigerenzer, G., Todd, P. and The ABC Research Group (Eds), Simple Heuristics That Make Us Smart, Oxford University Press, New York, NY, Oxford, pp. 37-58.

Goldstein, D.G. and Gigerenzer, G. (2002), "Models of ecological rationality: the recognition heuristic", Psychological Review, Vol. 109 No. 4, pp. 75-90.

Griggs, R.A. and Cox, J.R. (1982), “The elusive thematic-materials effect in Wason's selection task", British Journal of Psychology, Vol. 73 No. 3, pp. 407-420.

Hillert, A., Jacobs, H. and Muller, S. (2014), "Media makes momentum”, Review of Financial Studies, Vol. 27 No. 12, pp. 3467-3501.

Jensen, M.C. (1968), "The performance of mutual funds in the period 1945-1964”, Journal of Finance, Vol. 23 No. 2, pp. 389-416.

Katsikopoulos, K.V. and Martignon, L. (2006), "Naïve heuristics for paired comparisons: some results on their relative accuracy", Journal of Mathematical Psychology, Vol. 50 No. 5, pp. 488-494.

Lintner, J. (1965), "The valuation of risk assets and the selection of risky investments in stock portfolios and capital budgets", Review of Economics and Statistics, Vol. 47 No. 1, pp. 13-37. 
Lou, D. (2014), "Attracting investor attention through advertising”, Review of Financial Studies, Vol. 27 No. 6, pp. 1797-1829.

Merton, R.C. (1987), "A simple model of capital market equilibrium with incomplete information", Journal of Finance, Vol. 42 No. 3, pp. 483-510.

Mossin, J. (1966), "Equilibrium in a capital asset market”, Econometrica, Vol. 34 No. 4, pp. 768-783.

Pachur, T., Todd, P.M., Gigerenzer, G., Schooler, L.J. and Goldstein, D.G. (2011), "The recognition heuristic: a review of theory and tests", Frontiers in Psychology, Vol. 2, pp. 1-14.

Payne, J.W., Bettman, J.R. and Johnson, E.J. (1993), The Adaptive Decision Maker, Cambridge University Press, Cambridge, MA.

Ramanujam, V. and Venkatraman, N. (1984), “An inventory and critique of strategy research using the PIMS database”, Academy of Management Review, Vol. 9 No. 1, pp. 138-151.

Sharpe, W.F. (1964), "Capital asset prices: a theory of market equilibrium under conditions of risk", Journal of Finance, Vol. 19 No. 3, pp. 425-442.

Tetlock, P. (2007), "Giving content to investor sentiment: the role of media in the stock market", The Journal of Finance, Vol. 62 No. 3, pp. 1139-1168.

Tetlock, P. (2011), “All the news that's fit to reprint: do investors react to stale information?”, Review of Financial Studies, Vol. 24 No. 5, pp. 1481-1512.

Treynor, J. (1961), “Market value, time, and risk”, unpublished manuscript.

Treynor, J. (1962), “Toward a theory of market value of risky assets”, unpublished manuscript.

Tversky, A. and Kahneman, D. (1974), "Judgment under uncertainty - heuristics and biases", Science, Vol. 185 No. 4157, pp. 1124-1131.

\section{Corresponding author}

Luís Pacheco can be contacted at: luisp@upt.pt

For instructions on how to order reprints of this article, please visit our website: 